\title{
Uma árvore diferente: fractal exploratório na formação continuada de professores pedagogos
}

José Carlos Pinto Leivas*

\section{Resumo}

Neste artigo, apresentou-se uma pesquisa qualitativa, a qual teve por objetivo geral investigar visualização em uma construção fractal exploratória envolvendo geometria e formas, grandezas e medidas. Quanto à fundamentação teórica, foram empregadas concepções sobre a habilidade de visualização, destacando-se como ela pode ser explorada na obtenção de dados sobre sequências e padrões obtidos na construção da Árvore Fractal. A pesquisa foi realizada em uma aula na modalidade de ensino remoto, devido ao período de pandemia no transcorrer da disciplina oferecida em um programa de ação continuada a nível de mestrado. A atividade em questão foi dirigida a professoras com formação inicial em Pedagogia, todas em exercício. A aplicação foi feita via plataforma digital online e os dados foram coletados por meio de textos e imagens produzidas pelos seis participantes. Os resultados mostraram que é viável explorar uma outra geometria, tanto na formação continuada quanto na atividade profissional das participantes.

Palavras-chave: Árvore Pitagórica. Sequências e Padrões. Anos Iniciais.

* Doutor em Educação (Matemática) pela Universidade Federal do Paraná. Professor do Programa de Pós-Graduação em Ensino de Ciências e Matemática - Universidade Franciscana-UFN, Brasil. E-mail:leivasjc@ gmail.com

Recebido em: 08/10/2020; Aceito em: 26/04/2021

https://doi.org/10.5335/rbecm.v4i2.11609

http://creativecommons.org/licenses/by-nc-nd/4.0

ISSN: 2595-7376 


\section{Introdução}

O ensino de Geometria nos Anos Iniciais de escolaridade, antigamente também denominado primário, particularmente com a Independência do Brasil no início do século XIX, introduziu discussões importantes quanto a justificativas de sua inclusão nesse nível. A Matemática era ensinada por engenheiros, em geral, sem formação didática, oriundos de Portugal, os quais a conduziam em um nível inapropriado. Silva e Valente (2014), nos estudos históricos a respeito da inserção da Geometria nos primeiros anos escolares, indagam: [...] "Que geometria fez parte dessas primeiras discussões sobre sua inclusão na escola do ler, escrever e contar?" (p. 17). Para tais autores, o ensino de Geometria, no ensino primário, só foi se desenrolar no século XIX.

Piaget e Inhelder (1993) apontam aspectos psicológicos envolvidos na aprendizagem de Geometria, uma vez que, "[...] o espaço infantil, cuja natureza é ativa e operatória, começa por intuições topológicas elementares, bem antes de tornar-se simultaneamente projetivo e euclidiano". Nessa direção, Leivas, Hasselmann e Franke (2019) indicam possibilidades de explorar tais propriedades por meio da Banda de Möebius em pesquisas com participantes de diversos níveis de escolaridade. Também, Silva e Leivas (2014) realizam uma pesquisa com alunos em ação continuada em um mestrado profissional, na qual exploram alguns jogos topológicos, como o de pintar um mapa com um número reduzidos de cores.

Ainda, no quesito de envolver a psicologia na aprendizagem geométrica, não se pode deixar de evocar Dienes (1977), o qual reitera o dito por Piaget de que as primeiras noções nas crianças a respeito da Geometria independem de medidas. De acordo com o autor, "Uma criança preocupa-se muito pouco com a distância exata dos objetos, de seus movimentos ou do ângulo sob o qual as coisas são vistas" (p. 1). Aponta-se estudos e investigações atuais do autor deste artigo, as quais envolvem habilidades visuais no desenvolvimento de pensamento geométrico, ou seja, uma maneira de formar imagens mentais, com a finalidade de construir determinado conceito. Tal habilidade pode ser desenvolvida por diversos meios metodológicos e recursos didáticos. Para Arcavi (1999, p. 217),

visualização é a habilidade, o processo e o produto de criação, interpretação, uso e comentário sobre figuras, imagens, diagramas, em nossas mentes, em papel ou com ferramentas tecnológicas, com a finalidade de desenhar e comunicar informações, pensar sobre e desenvolver ideias não conhecidas e avançar na compreensão. 
Fischbein (1987), por sua vez, associa visualização à intuição para produzir conhecimentos auto evidentes da seguinte forma: " $E$ uma afirmação trivial que se tende naturalmente a pensar em termos de imagens visuais e o que não se pode imaginar visualmente é difícil de conceber mentalmente" (p. 103).

Assim sendo, em tempos de pandemia, em que atividades pedagógicas ocorrem de forma remota, justifica-se uma pesquisa realizada em uma aula nessa modalidade, destinada a professoras em ação continuada em um programa de mestrado profissional voltado a profissionais pedagogos que atuam na Educação Infantil e Anos Iniciais do Ensino Fundamental. Recursos materiais convencionais como esquadro e compasso, devido ao momento pandêmico, não estavam presentes no ambiente familiar, o que demandou improvisações e adaptações criativas para obtenção da denominada 'Árvore Fractal'. Portanto, preocupar-se com a formação do professor que ensina Matemática é um campo da Didática da Matemática que merece investigação nas seguintes temáticas: "Formação e desenvolvimento profissional do professor de matemática; o professor de matemática e a(s) prática(s) do professor; formação e desenvolvimento profissional do professor de matemática" (PONTE, 2020, p. 811).

\section{Procedimentos metodológicos}

Trata-se de uma pesquisa de cunho qualitativo no ensino, a qual, para Moreira (2011), tem o foco no próprio ensino. Nas palavras do autor, "Todavia, embora não haja, necessariamente, uma relação de causa e efeito entre ensino e aprendizagem, não faz muito sentido falar em ensino sem relacionar essa atividade a de aprender" (p. 15). Por tal razão, analisar como ocorre tanto o ensino, quanto a aprendizagem de um tema não trivial - Geometria Fractal - em uma aula no sistema remoto, na qual se empregam também construções e explorações de Geometria Plana, indica contribuições para o desenvolvimento de pensamento geométrico das participantes. Além disso, acredita-se que este tipo de atividade pode propiciar a disseminação de tais conteúdos em suas práticas profissionais.

A coleta de dados foi feita mediante os registros filmados ou fotografados pelas participantes e encaminhados por meio eletrônico ao professor-pesquisador. Tal processo levou em consideração, ainda, seu acompanhamento durante a realização da atividade realizada, a qual ocorreu via GoogleMeets.

No que diz respeito à análise, Rodríguez et al. (2016) afirmam ser preciso recorrer aos 'ingredientes' disponíveis na coleta de dados, dentre os quais destaca-se: 
[...] Pode ser um slogan, uma tarefa, uma lista de tarefas, o planejamento, o programa da matéria, a filmagem de uma aula, o registro escrito de uma aula, um livro e assim por diante. Seja próprio ou de terceiros, o documento deve estar disponível em papel, áudio ou vídeo, extraído da internet ou de outras fontes (p. 14) ${ }^{1}$.

Os sujeitos envolvidos na pesquisa foram alunas regularmente matriculadas em uma disciplina de um Mestrado Profissionalizante em Ensino de Ciências e Matemática, a qual é realizada de forma interdisciplinar, envolvendo um professor com formação matemática, que é o autor desta pesquisa e uma professora de Ciências Naturais. A disciplina é programada na tentativa de conectar o conteúdo sequências e padrões numéricos, no que diz respeito à Matemática, e filotaxia das plantas no tocante às Ciências Naturais. No que diz respeito ao conteúdo de ciências, a opção foi por investigar a classificação de elementos da Botânica e, para tal, a professora fez com que as participantes buscassem, ao seu redor, plantas para efetuar o estudo/ classificação. Essa conexão, particularmente, explorando sequências de Fibonacci encontradas na natureza foram motivadoras para desencadear o estudo das sequências numéricas no que diz respeito à Matemática.

Em uma primeira etapa da disciplina, as estudantes buscaram informações sobre filotaxia de plantas e as Sequências de Fibonacci, o que proporcionou um reconhecimento de padrões nas sequências ali visualizadas e formalizadas. Na segunda etapa, os sujeitos foram estimulados a conhecer uma nova geometria, denominada Fractal, com a qual se envolveram em algumas aulas e atividades, novamente, conectadas com fractais encontrados em ambiente natural. Para além de um mero reconhecimento desses fractais e dos respectivos padrões, foi proposta a construção da 'Árvore Fractal', a qual forneceria inúmeras possiblidades para o desenvolvimento de construções geométricas na prática profissional dos Anos Iniciais. Assim, definiu-se o seguinte objetivo geral da pesquisa: investigar visualização em uma construção fractal exploratória envolvendo geometria e formas, grandezas e medidas.

Para cumprir com tal objetivo, o professor-pesquisador fez um levantamento prévio da existência de recursos de desenho geométrico nas residências dos sujeitos, tais como esquadro, transferidor e compasso. Como todas são professores da Educação Infantil e Anos Iniciais do Ensino Fundamental, com formação inicial em Pedagogia, nenhuma possuía esses materiais. No entanto, todas dispunham de régua, lápis e canetas coloridas, além de livros de capa dura. Com isso, planejou-se a aula remota, adequando os recursos disponíveis à construção idealizada. O detalhamento dessa atividade será apresentado junto à análise dos dados. 
Seis sujeitos participaram da realização das tarefas, filmando ou fotografando seus registros durante o processo, de forma a constituir documentos próprios que foram encaminhados ao professor-pesquisador para análise. Tais indivíduos, todos profissionais em exercício, serão designados pelas siglas ${ }^{2}$ para evitar identificações, sendo eles: $P P_{1} ; P P_{2} ; P P_{3} ; P P_{4} ; P P_{5} ; P P_{6}$.

\section{Fundamentos teóricos}

O ensino de Geometria, particularmente no início da escolarização, como explanado na introdução deste artigo, ainda é recente no Brasil, e continua a promover discussões por pesquisadores que, na década de 1990, o consideravam abandonado (PAVANELLO, 2000). Lorenzato (2015, p. 14), ao abordar sobre a formação continuada, levanta os seguintes questionamentos: "para lecionar basta possuir um diploma universitário? O que é formação contínua? Ela é importante para quê? Quais opções de formação contínua têm sido oferecidas aos professores?”.

Além dessas considerações, chama-se atenção para o papel dos cursos em ação continuada, com os quais se tem envolvimento atual, particularmente nessa formação para profissionais pedagogos que atuam em uma área em que a inovação é primordial. Neste segmento, destaca-se o papel de dois grupos, um liderado por Lorenzato (2015) e outro pelo autor do presente artigo - GEPGEO, os quais ocupam-se diretamente com o ensino de Geometria nos diversos níveis, buscando atualizações para além de uma simples concepção euclidiana.

Biani (2015) analisa um projeto de ensino realizado pelo grupo liderado por Lorenzato, no qual uma das atividades desenvolvidas dizia respeito à localização em mapas. Nessa ocasião, os alunos, inicialmente, questionaram se era uma tarefa de Geografia ou de Matemática, ao que concluíram, após debates, ser "uma dedução intuitiva, mas já agregando algum conhecimento" (p. 67). Essa conclusão de um episódio de aula de $5^{\mathrm{o}}$ ano do Ensino Fundamental vai ao encontro do que Fischbein (1987, p. 19) aponta para a intuição como forma de produzir conhecimentos: "o papel essencial da intuição é conferir às componentes conceituais de um esforço intelectual as mesmas propriedades as quais garantem a produtividade e a eficiência adaptativa de um comportamento prático". O autor vai além ao indicar que as representações visuais "não somente auxiliam na organização da informação em representações como constituem importante fator de globalização [...]”. Além disso, 
uma imagem visual não apenas "[...]organiza os dados em estruturas significativas, mas é também um fator importante para orientar o desenvolvimento de uma solução analítica, representações visuais são essenciais dispositivos antecipatórios" (p. 104).

Com relação ao indicado, Lima e Carvalho (2014) abordam, em suas pesquisas sobre conversas com professores, que ensinam Geometria na atualidade, sobre as representações em geometria escolar serem importantes. Assim expressam: “Em todas as atividades mencionadas acima, o conhecimento geométrico é construído, gradativamente, com o auxílio de representações dos objetos do mundo físico [...] e, nesse processo, o sentido da visão desempenha um papel destacado" (p. 92). A partir disso, discorrem sobre visualização, em direção análoga ao que o autor do artigo tem abordado em pesquisas de sua autoria.

\section{Geometria fractal}

Neste item, traz-se algumas considerações a respeito de Geometria Fractal, uma das geometrias não euclidianas mais recentes, particularmente devido aos estudos de Mandelbrot, no século XX. De acordo com Janos (2009, p. 285), “A Geometria Fractal é uma linguagem matemática que descreve, analisa e modela as formas encontradas na natureza". Esta geometria está fundamentalmente ligada à teoria do Caos e, segundo Barbosa (2002, p. 9), “Ambas, Geometria Fractal e Caos se desenvolveram principalmente pelo rápido aprimoramento das técnicas computacionais”. No que diz respeito ao estudo desses objetos, o autor acrescenta: "A Matemática, em geral, fornece ao matemático, ao professor, e é bom que também ofereça ao educando, prazeres oriundos de várias formas de pensar e ver, ou de suas próprias ações” (p. 13).

A partir dessa última afirmação é que a presente pesquisa desenvolve-se, na medida em que oferece a professores da Educação Infantil e Anos Iniciais do Ensino Fundamental uma oportunidade de aprenderem, como educandos, novas formas de ensinar, explorando habilidades frequentemente prazerosas para esses sujeitos, como colorir, recortar, fazer atividades manuais e visuais.

Entende-se que, empregar Geometria Fractal em uma aula na modalidade remota (ou não), com profissionais trabalhando com crianças pequenas, pode permitir um avanço nos quesitos relacionados a números, sequências numéricas, visualização de formas geométricas planas e propriedades relacionadas. 
Fractais matemáticos são aqueles construídos a partir de regras matemáticas estabelecidas, como divisão em partes congruentes, no caso do Conjunto de Cantor; determinação de pontos médios de lados de um triângulo equilátero, no Triângulo de Sierpinski; exploração do Teorema de Pitágoras, no caso do presente artigo, na construção da Árvore Fractal.

Uma pesquisa no $3^{\circ}$ Ano do Ensino Médio com Geometria Fractal foi realizada por Picoli Sonza e Leivas (2018), em que foi explorado o papel dobradura em quatro etapas, cada uma envolvendo um dos fractais a seguir: Curva de Koch, Floco de Neve de Koch, Triângulo de Sierpinski e Árvore Bifurcada. Os autores concluíram que os participantes identificaram os fractais na natureza, bem como sua importância para o estudo em questão. Além disso, relacionaram o tema a outros tópicos de Matemática já estudados.

A exploração da Árvore Fractal no Ensino Fundamental e na Arquitetura foi realizada por Baier, Sedrez e Krindges (2012). Os autores mostram possibilidade de se estudar temas contemporâneos de Matemática que deveriam fazer parte dos currículos dessa disciplina, aspecto com o qual as pesquisas do autor do presente artigo corroboram. Os autores, em seu trabalho, apresentam algumas características da Geometria Fractal, assim como regras de construção obtidas por estudantes de um oitavo ano do Ensino Fundamental. Indicam, também, obras arquitetônicas que exploram fractais e que despertam o interesse dos estudantes para a Matemática.

Outra pesquisa com estudantes do Ensino Fundamental, em um $9^{\circ}$ ano, foi realizada por Picoli Sonza e Leivas (2018), dessa feita explorando a Teoria de Van Hiele, juntamente com o software Geogebra, na construção da Árvore Pitagórica. Os estudantes classificaram figuras geométricas de elementos da natureza obtidos por meio de fotografias, agrupando-os de acordo com as duas geometrias - Euclidiana e Fractal. Além disso, identificaram características de autossemelhança nos objetos fractais e concluíram que ambos os recursos foram decisivos para a compreensão do Teorema de Pitágoras e de sua aplicação.

A partir dessa rápida revisão, pode-se perceber as inúmeras possibilidades de explorar Geometria Fractal em níveis diferenciados de escolaridade e de situações de aplicação. Portanto, tem-se mais uma razão para a presente pesquisa, que se distingue das citadas por envolver professoras da Educação Infantil e Anos Iniciais em uma ação continuada. 


\section{A investigação e a análise dos dados.}

Como já explicitado, a pesquisa foi realizada no primeiro semestre de 2020, durante o período de pandemia e de forma remota. As estudantes já haviam estudado o tema sequências e padrões, especialmente na abordagem da filotaxia das plantas. Além disso, os pressupostos de Geometria Fractal também haviam sido tratados, uma vez que realizaram uma atividade envolvendo o Triângulo de Sierpinski com o uso de recortes em papel e colagem em uma folha colorida, determinando padrões em termos de perímetros e áreas dos triângulos. Inicialmente, na primeira aula da disciplina, haviam construído um cartão fractal, dando continuidade ao estudo dessa geometria nas aulas subsequentes.

O professor-pesquisador apresentou em PowerPoint no qual solicitava o material necessário para a realização da atividade, retomando o que havia indicado previamente (uma ou duas folhas A4 ou papel quadriculado/milimetrado); lápis, borracha, régua, canetinhas... (o que tivesse ao redor); um ou dois cantos retos duros (livros, cartolina, metal... o que estivesse ao alcance); material para fazer um diário de bordo da aula (o qual deveria ser devolvido por e-mail ao professor em um prazo de 48h).

No segundo slide, discutiu-se sobre o processo avaliativo do trabalho (Figura 1)

Figura 1: Indicativos do processo avaliativo.

\section{UMA ÁRVORE FRACTAL}

\section{Para avaliação}

Diário de borda da aula, o qual deverá ser devolvido até as $23 \mathrm{~h} .59$ de segunda-feira, constando:

- Os passos da construção realizada - justificando o que foi feito;

- Dificuldades na interpretação da tarefa;

- Aspectos positivos da tarefa;

- Aspectos negativos da tarefa;

- Conexões da atividade com a BNCC (síntese de um parágrafo ou dois);

- Conexões possiveis com sua prática profissional nos Anos Iniciais (idem).

- Avaliação crítica da aula (Idem). 
No que segue, foram propostas etapas e acompanhamento pela plataforma sobre o desempenho das participantes:

1) Marque na folha, na parte inferior, um segmento $\mathrm{AB}$, paralelo à base inferior, de $10 \mathrm{~cm}$ de comprimento e marque o seu ponto médio $\mathrm{C}$.

2) Pelo ponto médio $\mathrm{C}$ do segmento $\mathrm{AB}$, trace uma perpendicular e, sobre ela, um segmento com $8 \mathrm{~cm}$ de comprimento. Chame seu ponto extremo de D.

Durante a construção, o professor-pesquisador pode constatar algumas dificuldades, inicialmente, na compreensão do que deveriam realizar. Promoveu, assim, uma discussão com todas. Dienes (1977) reitera o dito por Piaget de que, nas crianças, as primeiras noções independem de medidas. Com este grupo focal não aconteceu diferente. Ao se questionarem como obter a perpendicular, sem que o proponente da atividade o dissesse, logo associaram tal fato ao que ele havia recomendado (terem um ou dois cantos retos duros - livros, cartolina, metal...). Assim, traçaram a perpendicular, uma vez que não houve dificuldade na compreensão da determinação do ponto médio $\mathrm{C}$ do lado $\mathrm{AB}$.

3) Trace paralela ao segmento $\mathrm{AB}$ (ou perpendicular ao $\mathrm{CD}$ ), passando pelo ponto D.

Para a realização dessa tarefa, houve um hiato considerável por partes das participantes, até que $\mathrm{PP}_{4}$ promoveu uma explosão, enquanto as demais questionavam como proceder: "coloca um livro com o dorso no segmento $A B$, bem pertinho de A e deixa o dorso para dentro e firma bem. Tira o primeiro e escora no segundo fazendo ele passar por D e passa uma reta” $\left(P P_{4}\right)$. Ao que tudo leva acreditar, essa participante explorou sua intuição, no sentido indicado por Fischbein (1987, p. 19), ou seja, utilizar tal habilidade para produzir conhecimentos. Em outras palavras, a intuição é o esforço intelectual que garante produtividade e eficiência adaptativa de um comportamento prático. Assim, todas seguiram a sugestão e obtiveram a linha paralela ao segmento $\mathrm{AB}$. O professor-pesquisador, vale ressaltar, não teve preocupação maior com a formalização conceitual.

Na sequência, encaminhou o seguinte (Figura2):

4) Marque um segmento $\mathrm{DE}$, com $5 \mathrm{~cm}$, nessa paralela para a direita, e outro $\mathrm{DF}$, também de $5 \mathrm{~cm}$, para a esquerda.

5) Obtenha os quadrados DEHG e DFKG. 
Figura 2: Construção do professor-pesquisador

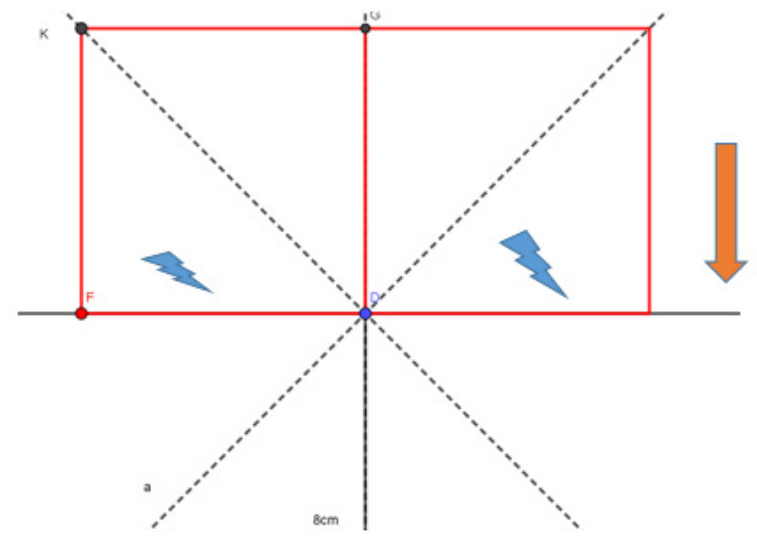

No que segue, apresenta-se as primeiras construções realizadas por $P P_{6}$ (Figura 3) e encaminhadas por e-mail ao professor-pesquisador, de modo a atender ao que segue.

6) Trace as retas DH e DK.

7) Marque sobre a reta $\mathrm{DH}$ o semento DL com a metade da medida de CD e o mesmo sobre DK (DJ).

8) Apague os quadrados

Figura 3: Elaborado por $P P_{6}$.
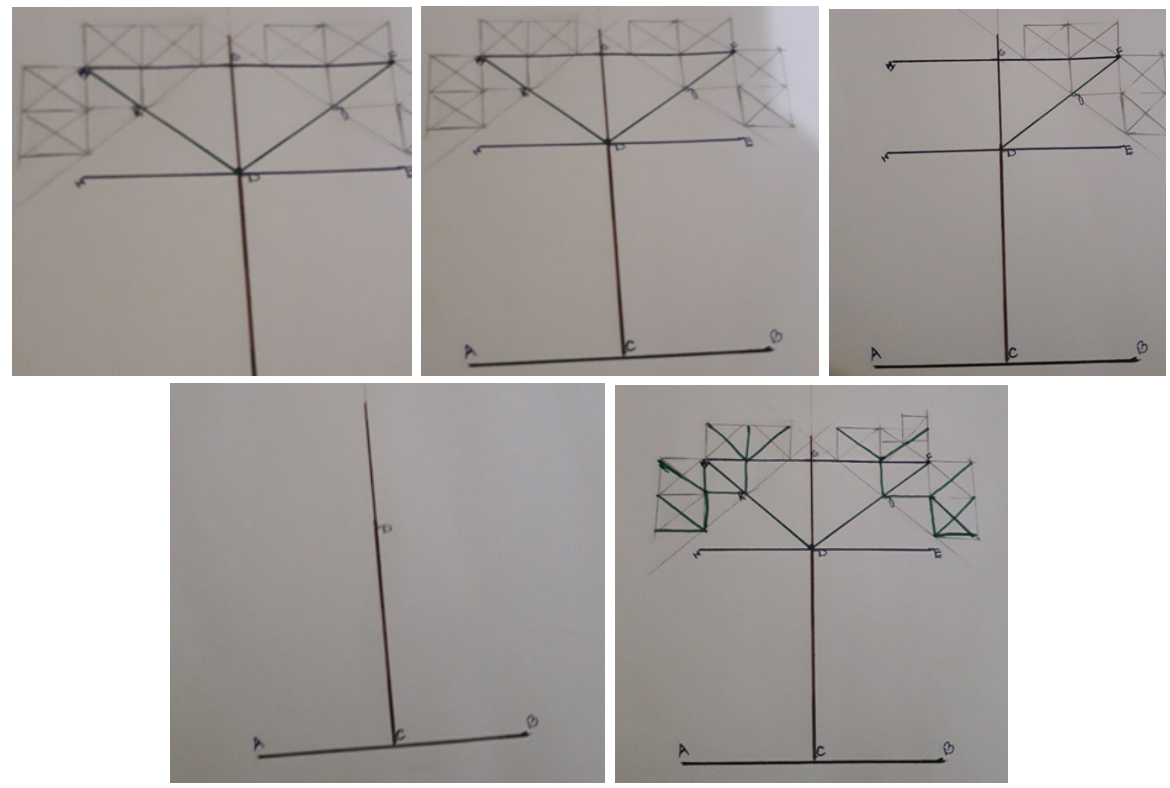
Salienta-se que as estudantes não dispunham de transferidor, de modo a obterem as bifurcações da árvore para obter o padrão fractal. O professor-pesquisador, por essa razão, ao utilizar os livros/régua, optou por obter o ângulo de $45^{\circ}$, uma vez que ele corresponde àquele formado pela diagonal do quadrado com um de seus lados. Dessa forma, seria viável a construção sem o instrumento apropriado, isto é, o transferidor. Percebe-se que a sequência apresentada por $P P_{6}$ satisfaz plenamente, visto que a estudante, assim como as demais, apoderou-se da 'ferramenta' adaptada. Como ilustra a Figura 3, a utilização de livros para a obtenção de ângulos retos permitiu a bifurcação da árvore, o que vai ao encontro do dito por Arcavi (1999) sobre o processo e o produto de criação no desenvolvimento de visualização desse objeto fractal.

Na Figura 4 são ilustradas outras etapas da construção da árvore fractal explorando os recursos adaptados para a tarefa realizada por $P P_{5}$. Essa participante explorou o papel quadriculado, diferentemente das demais que usaram o papel ofício. Deste modo, recorreu a outra forma de obtenção dos quadrados. Importante destacar que fora solicitado reunirem o tipo de material que havia disponível nas residências individuais, sendo que apenas essa participante dispunha do papel quadriculado. Destaca-se, também, que ela foi bastante criativa e não pediu auxílio ou orientação para obter as diagonais, usando o lado do quadradinho como unidade de medida.

Figura 4: Construção de $P P_{5}$.

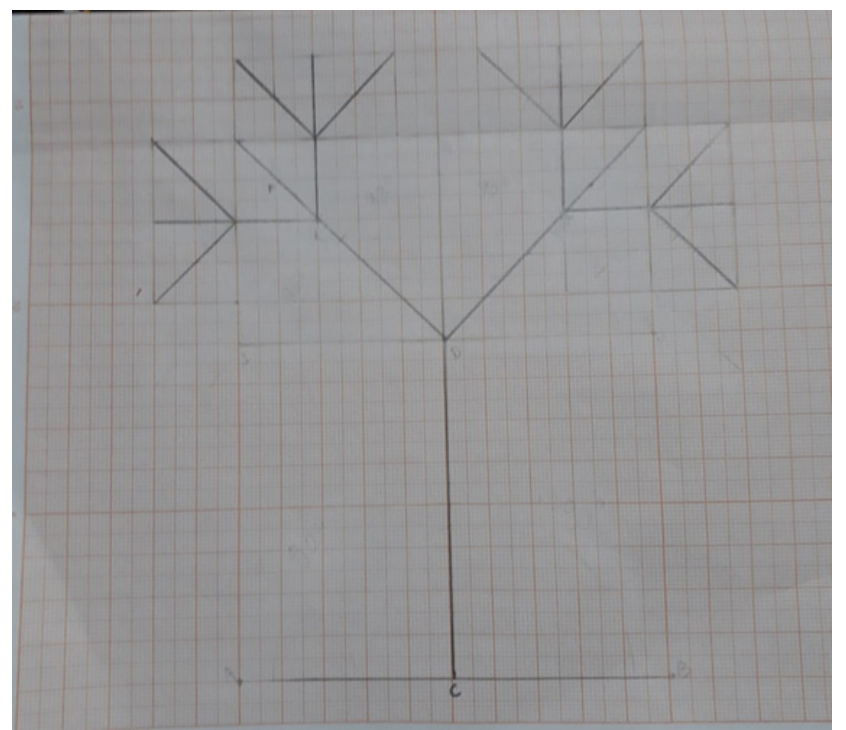


Para finalizar a construção, foi indicado:

9) Formar quatro novos quadrados, conforme o material que dispuser. Estes devem ter um lado sobre as retas assinaladas, um para um lado e o outro para o outro.

Na Figura 5, apresenta-se a construção realizada pelo professor no Geogebra, bem como sua finalização.

Figura 5: Dados do professor-pesquisador.
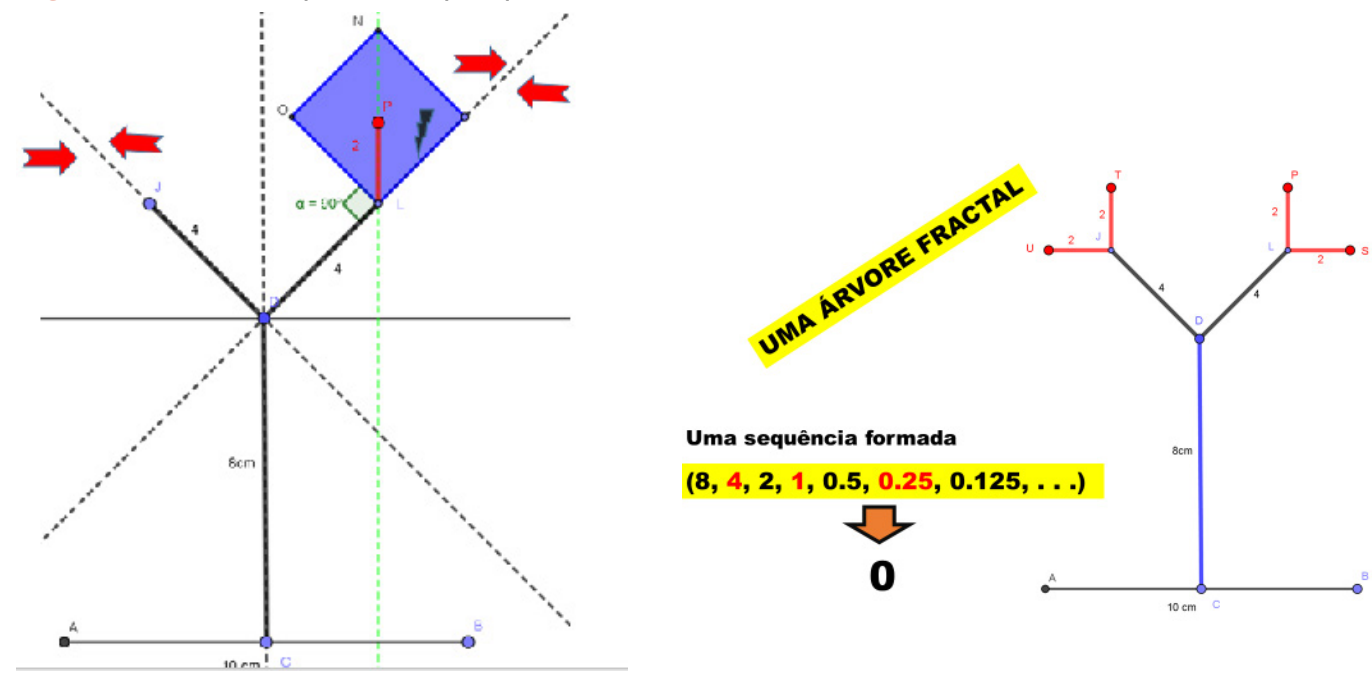

$\mathrm{Na}$ figura da esquerda, estão orientações para a construção dos quadrados na primeira iteração, a fim de obter diagonais correspondentes às ramificações de $45^{\circ}$ e, na da direita, a árvore com os traços auxiliares já eliminados. A seguir, constam explorações a partir do andamento das construções que foram feitas, como a determinação dos padrões.

Construída a Árvore Fractal, deu-se início a outra etapa da investigação, que consistia na busca dos padrões encontrados. Para isso, distribuiu-se, antecipadamente, o Quadro 1, para ser preenchido durante as construções. 
Quadro 1: Dados coletados durante a construção da Árvore Fractal.

\begin{tabular}{|c|c|c|}
\hline & \multicolumn{2}{|c|}{ Constituintes da Árvore Fractal } \\
\hline Interação & Quantidade de segmentos & Quantidade de segmentos em forma de potenciação \\
\hline 0 & & \\
\hline 1 & & \\
\hline 2 & & \\
\hline 3 & & \\
\hline 4 & & \\
\hline$\ldots$ & & \\
\hline $\mathrm{n}$ & & \\
\hline
\end{tabular}

Embora a coleta de dados possa parecer simples, ela foi relevante para os sujeitos da pesquisa, uma vez que os auxiliou na organização das tarefas e permitiu que tirassem conclusões corretas no que diz respeito aos padrões e sequências que podem ser obtidas nos objetos fractais. Particularmente, esses padrões ocorrem naqueles fractais construídos matematicamente, os quais, no presente caso, foram também explorados geometricamente, indo ao encontro do que preconiza a BNCC.

Assim, foram propostos os seguintes questionamentos:

Quantos segmentos foram construídos na segunda iteração? Quantos segmentos seriam construídos na $5^{\underline{a}}$ iteração? Qual é a razão (divisão) entre os segmentos na $1^{\underline{a}}$ e na $2^{\underline{a}}$ iteração? Qual é a razão entre os segmentos na $2^{\underline{a}}$ e na $3^{\underline{a}}$ iteração? Ainda, escreva a lei matemática que determina o número de segmentos em função do número de iterações. No que segue, apresenta-se os dados e conclusões de algumas participantes.

$P P_{5}$

Quadro 2: Dados fornecidos por $P P_{5}$.

\begin{tabular}{|c|c|c|}
\hline Iteração & Quantidade de segmentos & Quantidade de segmentos em forma de potência \\
\hline 0 & 2 & $2^{1}$ \\
\hline 1 & 4 & $2^{2}$ \\
\hline 2 & 8 & $2^{3}$ \\
\hline 3 & 16 & $2^{4}$ \\
\hline 4 & 32 & $2^{5}$ \\
\hline$\ldots$ & 64 & $2^{6}$ \\
\hline $\mathrm{n}$ & & \\
\hline
\end{tabular}


A participante interpretou que, na primeira iteração, havia o segmento horizontal e o vertical, logo 2 . Indicou, para a posição 5 , localizada na linha com pontinhos, o valor correto de 64 segmentos. Portanto, $2^{6}$, ou seja, não se deu conta que essa era a quinta posição e, então, poderia retomar a escrita e escrever $2^{5}$, retificando os anteriores. Talvez por isso, embora conseguisse escrever as potenciações corretamente, não expressou a generalização para n. Ela iniciou com 2 segmentos e com o expoente 1, quando ainda não havia iteração. Talvez, por isso, não tenha conseguido a expressão $2^{\text {n+1 }}$. Finalizando, a participante escreveu que a razão entre os comprimentos era de 0,5. No entanto, como pode ser verificado no Quadro 2, ela não conseguiu escrever a lei matemática que expressa o número de segmentos em função do número de iterações. Essa finalização remete diretamente ao questionamento feito por Lorenzato (2015), quando argumenta que determinadas abordagens na formação continuada não bastam para lecionar, tampouco um diploma superior. No que segue, apresenta-se os dados fornecidos por $P P_{4}$. A estudante, a exemplo da anterior, demonstrou limitações na formalização das potenciações, particularmente por ter interpretado a iteração 0 como isenta de segmentos e, no caso, a expressão pode ter sido considerada coerente (Quadro 3). Já na segunda linha, ela interpreta como tendo um único segmento e completa com $1^{1}$.

Quadro 3: Dados fornecidos por $P P_{4}$.

\begin{tabular}{|c|c|c|}
\hline Iteração & Quantidade de segmentos & Quantidade de segmentos em forma de potência \\
\hline 0 & 0 & $0^{1}$ \\
\hline 1 & 1 & $1^{1}$ \\
\hline 2 & 2 & $2^{1}$ \\
\hline 3 & 4 & $2^{2}$ \\
\hline 4 & 8 & $2^{3}$ \\
\hline$\ldots$ & 16 & $2^{4}$ \\
\hline $\mathrm{n}$ & $\mathrm{N}^{0}$ segmentos anteriores $\mathrm{x} 2$ & $2^{\mathrm{n}^{\text {o }} \text { interaçöes }-1}$ \\
\hline
\end{tabular}

$\mathrm{PP}_{4}$ interpreta que, na segunda iteração, há "2 segmentos formando os $1^{\text {os }}$ galhos da árvore". Responde aos demais itens coerentemente, indicando que a razão seria a metade, e escreve a lei matemática de modo correto, ainda que não tão bem formalizada. Reporta-se, neste ponto, à visualização sugerida por Fischbein (1987) que, aliada à intuição, produz conhecimentos auto evidentes a partir de uma afirmação trivial pensada em termos de imagens visuais. 
$\mathrm{PP}_{3}$ informa: "Observei a construção feita anteriormente e completei a tabela", a qual consta do Quadro 4.

Quadro 4: Dados fornecidos por $P P_{3}$.

\begin{tabular}{|c|c|c|}
\hline Iteração & Quantidade de segmentos & Quantidade de segmentos em forma de potência \\
\hline 0 & 1 & $2^{\circ}$ \\
\hline 1 & 2 & $2^{1}$ \\
\hline 2 & 4 & $2^{2}$ \\
\hline 3 & 8 & $2^{3}$ \\
\hline 4 & 16 & $2^{4}$ \\
\hline 5 & 32 & $2^{5}$ \\
\hline $\mathrm{n}$ & 64 & $2^{\mathrm{n}+1}$ \\
\hline
\end{tabular}

Essa estudante destacou-se pela expressão correta das potenciações, tendo começado pela iteração 0 como sendo a primeira. Ao responder aos questionamentos, explicita que, na segunda iteração, há 2 segmentos e na quinta, 16. Conclui que o número de segmentos vai dobrando e indica corretamente a generalização, isto é, $2^{\mathrm{n}+1}$. Ela fornece, ainda, a seguinte explicação: "De um galho central vão surgir galhos secundários e dos secundários surgem outros e assim por diante e normalmente observa-se a diminuição do tamanho desses galhos".

Ao analisar os dados fornecidos por $\mathrm{PP}_{3}$, retoma-se o indicado por Rodríguez et al. (2016), ao afirmarem ser preciso recorrer aos elementos capturados em um documento disponibilizado a partir da realização de uma aula. Essa análise do documento fornecido por $P P_{3}$ vai ao encontro da aquisição de habilidades visuais como preconizado por Arcavi (1999), as quais promovem um processo de criação, interpretação e uso de figuras e imagens reproduzidas em papel.

Para concluir as análises da atividade, foi pedido que as participantes indicassem dificuldades na interpretação da tarefa; aspectos positivos; aspetos negativos; conexões da atividade realizada com o que indica a BNCC; possibilidades de uso na prática profissional das participantes. Apresenta-se os depoimentos de duas das participantes. 
$P P_{1}$

Dificuldades na interpretação da tarefa.

"No início da atividade que era a construção da árvore fractal parecia que era fácil a sua construção, mas no decorrer da atividade não sei por que, ficou um pouco complicado nas medidas das ramificações da árvore, o importante que no final deu tudo certo".

Aspectos positivos da tarefa.

"Para mim foi de grande relevância essas propostas de aula fazendo com que a curiosidade crescesse a cada aula fazendo com que me tornasse pesquisadora de cada tema abordado em sala de aula. Assim, podemos perceber que a matemática pode ser trabalhada de várias maneiras, deixando o seu conteúdo mais prazeroso".

Aspectos negativos da tarefa

"O único negativo, para mim que não foi em aula presencial, mas valeu o desafio".

\section{Conexões da atividade com a BNCC}

"Alguns fractais são construídos conforme a BNCC a partir de objetos geométricos estudados na educação básica, tais como segmentos de reta, triângulos e quadrados. Outros são construídos por meio de programas computacionais com a utilização de dezenas de cores, apresentam uma movimentação com forte apelo estético e, numa visão superficial".

Conexões possíveis com sua prática profissional nos Anos Iniciais

"Sim, as práticas pedagógicas podem e devem ser trabalhadas sempre que possível desde o maternal até o ensino superior sobre os fractais como um conteúdo criativo na matemática, fazendo com que a matemática deixe de ser aquele bicho que todo estudante acha para ser uma aula prazerosa cheia de mistério, criatividade e descoberta".

No que segue, $P P_{5}$ apresenta seus depoimentos de forma sequencial.

"A árvore fractal foi construída a partir de iterações feitas, com material improvisado que cada pessoa dispunha no momento. Essas iterações foram aumentando, dando a forma de árvore. Eu senti dificuldades para interpretar a tarefa a partir do momento que tive que realizá-la sozinha. Aí refiz tudo novamente, seguindo os slides que o professor enviou".

Aspectos positivos da aula

"Realizar a partir da geometria atividades práticas e motivadoras. Utilizar na realização da atividade materiais que temos em casa".

Aspectos negativos

"Insegurança em relação ao que eu entendi e o que o professor esperava..." 
"De acordo com a BNCC este conteúdo pode ser trabalhado com o quinto ano do Ensino Fundamental, observando a proporção, a partir do aumento do número de segmentos e a diminuição do tamanho dessas iterações. (EF05MA18) Reconhecer a congruência dos ângulos e a proporcionalidade entre os lados correspondentes de figuras poligonais em situações de ampliação e de redução em malhas quadriculadas e usando tecnologias digitais".

"Essa atividade pode ser explorada nos anos iniciais de inúmeras maneiras, dependendo do objetivo do professor. (EF05MA14) Utilizar e compreender diferentes representações para a localização de objetos no plano, como mapas, células em planilhas eletrônicas e coordenadas geográficas, a fim de desenvolver as primeiras noções de coordenadas cartesianas".

"Além de trabalhar a matemática, podem ainda dar introdução a interpretação de plantas baixas em malhas quadriculadas".

\section{Considerações finais}

Neste artigo apresentou-se análise de uma pesquisa realizada no primeiro semestre do ano de 2020, com uma turma em ação continua em um mestrado profissional. Envolveu seis professoras da Educação Infantil e Anos Inicias, todas com formação inicial em Pedagogia. A disciplina tinha como pressuposto curricular a abordagem de números. O professor da turma, autor do presente artigo, buscou desenvolver o conteúdo por meio de uma construção fractal, uma vez que, no primeiro dia de aula, já havia dado alguns indicativos dessa geometria na exploração de sequências numéricas e padrões na construção de um cartão fractal.

A pesquisa teve por objetivo investigar visualização em uma construção fractal exploratória envolvendo geometria e formas, grandezas e medidas. Após o preenchimento de um quadro com medidas obtidas durante a construção da Árvore Fractal, os estudantes encaminharam este documento ao professor-pesquisador, o qual os utilizou para realizar a análise dos dados.

A opção por este fractal prendeu-se ao fato de que ele permitiu ir além da utilização de recursos convencionais como esquadros, compasso e transferidor. Além disso, pelo fato de a atividade ser desenvolvida no ambiente domiciliar de cada participante individualmente e de modo remoto. $\mathrm{O}$ fato de vivenciar-se o momento de pandemia implicou no entendimento da necessidade de adaptar situações/materiais e alternativas didático/metodológicas para o ensino e a aprendizagem matemática, especialmente por tratar-se de uma disciplina de um mestrado profissional em ensino. 
Outra razão pela escolha deste fractal é que ele permite explorar tanto geometria e formas quanto grandezas e medidas, recomendadas nos conteúdos e habilidades da BNCC. Assim, entende-se e pesquisa-se sobre habilidade de visualização e, nessa situação, foi possível explorá-la na obtenção de padrões e sequências, inclusive o envolvimento com potenciação, o que não é muito frequente na formação inicial desses sujeitos.

Os resultados da pesquisa mostram que elementos visuais e conteúdos geométricos foram explorados e que permitiram aprimorar o nível de desenvolvimento de pensamento geométrico das participantes. Por sua vez, o envolvimento desses sujeitos, avaliando a realização da atividade, apontando aspectos positivos e negativos e, sobretudo, indicando sua viabilização junto às suas práticas profissionais, indicam que a opção por tal metodologia na referida atividade com Geometria Fractal pode ser utilizada em qualquer nível de escolaridade, desde que adaptada didaticamente.

Espera-se que tal pesquisa possa contribuir para que outros profissionais que atuam no nível de ensino investigado possam fazer uso dessa atividade, aproveitando-a como sugestão de como é possível ser realizada durante o ensino remoto.

\section{A different tree: exploratory fractal in continuing teacher education}

\section{Abstract}

In this article, a qualitative research was presented, which had the general objective of investigating visualization in an exploratory fractal construction involving geometry and shapes, quantities and measures. As the main theoretical foundation, conceptions about the ability of visualization and how it can be explored in obtaining data on sequences and patterns obtained in the construction of the Fractal Tree were used. The research was carried out in a class, in the remote teaching modality, due to the period of pandemic that occurred during the course offered in a program of continuous action at the master's level aimed at teachers with initial training in Pedagogy, all in exercise. The application was made through an online digital platform and data were collected through texts and images produced by the six participants. The results showed that it is feasible to explore a geometry other than Euclidean and to be developed in their practices.

Keywords: Pythagorean Tree. Sequences and Patterns. Early Years. 


\section{Notas}

1 “[...] Puede ser una consigna, una tarea, un listado de tareas, la planificación, el programa de la materia, la filmación de una clase, el registro escrito de una clase, un libro, etcétera. Ya sea de autoría propia o ajena, el documento debe estar disponible en papel, audio o video, extraído de internet u otras fuentes"

2 A sigla PP foi utilizada com as iniciais das palavras Professor Pedagogo seguidas de índice numérico.

\section{Referências}

ARCAVI, A. The role of visual representation in the learning of mathematics. In: NORTH AMERICAN CHAPTER OF THE PME, 1999. Proceedings... Disponível em: <http://www.clab.edc.uoc. gr/aestit/4th/PDF/26.pdf>. Acesso em: 30 jun. 2020.

BAIER, T.; SEDREZ, M. R.; KRINDGES, E. E. ÁRVORES FRACTAIS NO ENSINO FUNDAMENTAL E NA ARQUITETURA. Anais... IV Jornada Nacional de Educação Matemática; XVII Jornada Regional de Educação Matemática. Passo Fundo, UPF, 2012.

BARBOSA, Ruy Madsen. Descobrindo a Geometria Fractal (para sala de aula). Belo Horizonte: Autêntica, 2002.

BIANI, R. P. Uma proposta didática para a Geometria. In: LORENZATO, S. (org.) Aprender e ensinar geometria. Campinas, SP: Mercado das Letras, 2015. p. 57-98.

DIENES, Z. P. Exploração do espaço: primeiros passos em matemática. 3 ed. rev. São Paulo: EPU; 1977.

FISCHBEIN, E. Intuition in science and mathematics: an educational approach. London: Mathematics Education Library, 1987.

JANOS, M. GeometrIa fractal. Rio de Janeiro: Ciência Moderna, 2009.

LEIVAS, J. C. P., HASSELMANN, A. D., FRANKE, R. F. Faces da Banda de Möebius. REnCiMa, v. 10, n. 3, p. 93-110, 2019.

LIMA, P. F; CARVALHO, J. B. P. de. A GEOMETRIA ESCOLAR HOJE: CONVERSANDO COM O PROFESSOR QUE ENSINA MATEMÁTICA. In: SILVA, M.C.L. da; VALENTE, W.R. (org.). A Geometria nos primeiros anos escolares - história e perspectivas atuais. Campinas, SP: Papirus Editora, 2014.

LORENZATO, S. (org.) Aprender e ensinar geometria. Campinas, SP: Mercado das Letras, 2015.

MOREIRA, M. A. Metodologias de Pesquisa em Ensino. São Paulo: Editora Livraria da Física, 2011.

PAVANELLO, R. Geometria e construção de conceitos aritméticos: investigando algumas inter-relações. POSTER. In: Reunião Anual da ANPEd, 23., Caxambu, MG, 2000. Disponível em: <http://paje.fe.usp.br/ anped/> Acesso em: 1 jul. 2020.

PIAGET, J.; INHELDER, B. A representação do espaço na criança. Porto Alegre: Artes Médicas, 1993. 
RODRÍGUEZ, M.; BARREIRO, P.; LEONIAN, P.; MARINO, T.; POCHULU, M. D. (compilado por Mabel Rodríguez). Perspectivas metodológicas en la enseñanza y en la investigación en educación matemática. 1ed. Los Polvorines: Universidad Nacional de General Sarmiento, 2016.

SILVA, M. C. L. da; VALENTE, W. R. (org.). A Geometria nos primeiros anos escolares história e perspectivas atuais. Campinas, SP: Papirus Editora, 2014.

SILVA., E. S. da; LEIVAS, J. C .P. Algumas propostas intuitivas para a aquisição de propriedades topológicas no Ensino Fundamental e Médio. Anais... VI EEMAT - Encontro de Educação Matemática do Estado do Rio de Janeiro. UFF, Niterói, 2014.

PICOLI SONZA, A., LEIVAS, J. C. P. Explorando a Geometria Fractal no Ensino Médio por meio de uma Oficina Pedagógica. REVISTA THEMA. V.15, n. 4, 2018. p. 1549- 1561.

PONTE, J. P. A didática da matemática e o trabalho do professor. RBECM, Passo Fundo, v. 3, n. 3, p. 809-826, ed. espec. 2020. 